\title{
DENERVATION CHANGES IN MAMMALIAN STRIATED MUSCLE*
}

BY

\section{S. SUNDERLAND and L. J. RAY}

\author{
From the Department of Anatomy and Histology, University of Melbourne, Australia
}

The object of the experimental enquiry which forms the subject of this paper was to determine the period for which denervated mammalian striated muscle retains its essential morphological features and the manner in which these features are ultimately modified as the period of denervation increases. In order to obtain this information it was necessary to extend the period of denervation well beyond the limits which have hitherto been employed. Few of the previous enquiries devoted to a consideration of this problem have been concerned with the gross and microscopic changes occurring in a muscle which has been deprived of its nerve supply; in those which have attention has been confined to the first few months of the process, though Tower (1935) extended her observations to cover the first year of denervation.

\section{Material and Methods}

The experiments were performed on 36 adult specimens of the Australian opossum, Trichosurus vulpecula. The duration of denervation in the shortest experiment was nine days and in the longest $\mathbf{4 8 5}$ days. The muscles selected for examination were the flexor carpi ulnaris, flexor carpi radialis, and pronator teres. These muscles are readily identified and have well-defined attachments from which they may be rapidly and easily separated.

Under chloroform anæsthesia and with aseptic technique the median and ulnar nerves were removed on the left side between the axilla and the elbow. In 27 specimens the two nerves were interrupted at the one operation, the ulnar nerve only in three, and in six the ulnar segment was removed before the median, a variable interval elapsing between the two operations. After division the nerve ends were treated in order to prevent regenerating axons from reaching the distal stump or the denervated muscles directly. At the conclusion of each experiment the distal stumps were examined histologically in order to ascertain whether or not the measures adopted had been effective. Regenerating axons had reached the distal stump of six of the severed ulnar nerves and four of the median, and these specimens were consequently discarded. In the remainder denervation had been complete and permanent.

The wounds healed rapidly and by primary intention. The involved limb adopted a characteristic attitude post-

* This work was assisted by a grant from the National Health and Medical Research Council of Australia. operatively with the forearm supinated and the hand hyperextended. Elbow movements were unimpaired. Flexion at the wrist could not be performed voluntarily, but the joint remained mobile so that the hand was intermittently forced into flexion by the movements of the animal in its cage. The hyperextension at the wrist was such that, though the flexores carpi muscles arise above the elbow and are relaxed by elbow flexion, these two muscles must have been almost permanently stretched as a result of the deformity, particularly the flexor carpi ulnaris which has an additional origin below the elbow. Despite the supinated position of the forelimb the pronator teres was stretched and relaxed as the elbow was extended and flexed respectively. Trophic ulcers involved the digits shortly after the operation. These healed either with or without sloughing of one or more digits; the latter was common. In the long term experiments there was no persistent ulceration. The animals remained healthy throughout the investigation and none lost weight. They were allowed the full freedom of a large cage so that their normal activities were unrestricted.

The experiments were terminated after varying periods. At the conclusion of each experiment the nerve stumps and muscles were exposed under general anæsthesia and a note was made of their gross appearance and any difficulties in exposure such as adherence to deep fascia. A search was also made for fibrillation. The proximal and distal segments of the severed nerves together with the median and ulnar nerves on the contralateral side were removed for study. The animal was then killed and the three muscles carefully removed on both sides by employing a standard technique. The muscles were weighed to the nearest milligram and then transferred to $10 \%$ formalin. Care was taken to ensure that the same interval elapsed between removal and weighing in each case. There are several sources of error in obtaining the weight of wet specimens and in employing, as was the method adopted in this study, the weight of the corresponding non-denervated muscle as the preoperative weight of the denervated muscle for calculating the percentage atrophy. These errors have been detailed by Iangley $(1916 ; 1917)$ and Langley and Hashimoto (1918). All the precautions outlined by them were observed in the present enquiry. In the case of lateral differences in the weight of corresponding muscles Langley (1917) wrote, for the cat, that " in considering the degree of atrophy, a difference of 5 per cent. on the two sides must be disregarded, and a difference of 5 to 10 per cent. treated with caution" 
TABLE I

LATERAL DIFFERENCE IN WEIGHT OF CORRESPONDING MUSCLES EXPRESSED AS A PERCENTAGE OF THE HEAVIER OF THE TWO

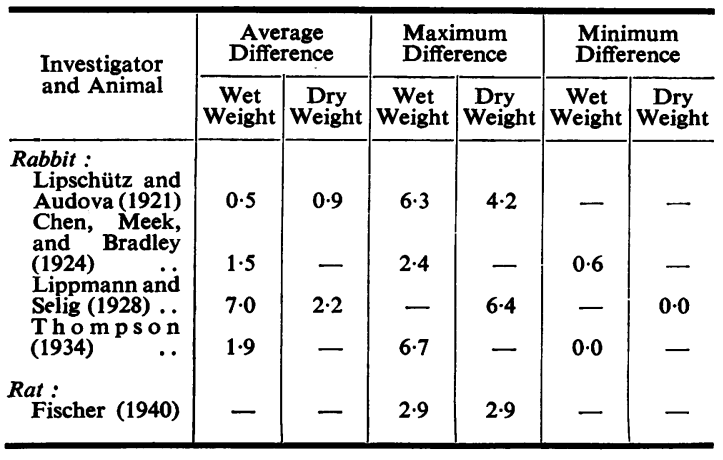

while for the rabbit Langley and Hashimoto (1918) concluded that " any one muscle in any one animal may be about 6 per cent. to about 9 per cent. heavier on one side than on the other ". The lateral differences obtained by other investigators are given in Table $\mathbf{I}$. The lateral differences in the opossum are consistent with those reported by Langley for other animals nor were they such as to destroy the validity of the curve of atrophy which has been constructed from the calculated percentage weight loss.

The duration of the individual experiments together with the percentage weight loss in each case are given in Table II.

The muscles were submitted to a standard histological procedure. After fixation in formalin they were transected at the mid-point of the belly. After embedding the material in paraffin in the usual manner, transverse sections, $10 \mu$ in thickness, were prepared from the four

TABLE II

DURATION OF DENERVATION AND PERCENTAGE ATROPHY OF MUSCLES

\begin{tabular}{|c|c|c|c|c|}
\hline \multirow{2}{*}{ Specimen } & \multirow{2}{*}{$\begin{array}{l}\text { Duration of } \\
\text { Denervation } \\
\text { (Days) }\end{array}$} & \multicolumn{2}{|c|}{ Median Nerve } & \multirow{2}{*}{$\begin{array}{c}\text { Ulnar Nerve } \\
\begin{array}{c}\text { Flexor Carpi } \\
\text { Ulnaris }\end{array}\end{array}$} \\
\hline & & Pronator Teres & $\begin{array}{l}\text { Flexor Carpi } \\
\text { Radialis }\end{array}$ & \\
\hline 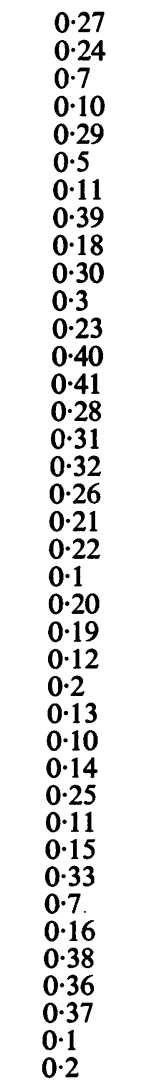 & $\begin{array}{r}9 \\
9 \\
12 \\
12 \\
16 \\
21 \\
29 \\
34 \\
35 \\
44 \\
49 \\
59 \\
60 \\
68 \\
76 \\
76 \\
78 \\
89 \\
112 \\
112 \\
135 \\
140 \\
172 \\
181 \\
185 \\
196 \\
198 \\
224 \\
229 \\
231 \\
252 \\
254 \\
255 \\
280 \\
335 \\
426 \\
432 \\
444 \\
485\end{array}$ & $\begin{array}{r}0 \\
10 \\
4 \\
23 \\
30 \\
40 \\
44 \\
57 \\
55 \\
54 \\
64 \\
59 \\
56 \\
71 \\
60 \\
63 \\
72 \\
71 \\
65 \\
69 \\
64 \\
73 \\
69 \\
76 \\
74 \\
62 \\
80 \\
78 \\
59 \\
- \\
-\end{array}$ & $\begin{array}{r}0 \\
20 \\
10 \\
22 \\
14 \\
29 \\
43 \\
50 \\
45 \\
40 \\
63 \\
53 \\
53 \\
65 \\
52 \\
56 \\
70 \\
65 \\
66 \\
70 \\
65 \\
76 \\
64 \\
78 \\
69 \\
65 \\
80 \\
68 \\
61 \\
-\end{array}$ & $\begin{array}{l}0 \\
3 \\
\overline{30} \\
36 \\
\overline{30} \\
33 \\
29 \\
31 \\
51 \\
35 \\
43 \\
53 \\
60 \\
66 \\
60 \\
51 \\
54 \\
61 \\
64 \\
68 \\
76 \\
54 \\
57 \\
74 \\
59 \\
71 \\
68 \\
69 \\
63 \\
69\end{array}$ \\
\hline
\end{tabular}


faces of the two blocks into which each muscle had been divided. The remainder of each block was then sectioned longitudinally at $10 \mu$. In this way transverse and longitudinal sections were obtained from the same muscle. These were stained with hæmatoxylin and eosin and Van Gieson.

Values for the percentage reduction in the calibre of the muscle fibres as atrophy progressed were obtained in the following manner. Transverse sections from the middle of the denervated and corresponding nondenervated muscles were enlarged by a microprojector to a constant magnification of 450 diameters and the outline of the fibres drawn. The cross-sectional area of the muscle occupied by its fibres was then measured with a planimeter. From these measurements average values were obtained for the cross-sectional area of a normal and an atrophied fibre and these were employed for calculating the percentage muscle fibre atrophy. An examination of transverse sections from the nondenervated muscles revealed little variation in the calibre of the fibres when these were examined in sections taken from the middle of the muscle and that at this level the majority of the fibres were at their maximum width. It was for this reason that planimeter measurements were made on sections taken at this level.

Macroscopic Features of the Denervated Muscle At no stage of denervation did the muscle give the appearance of becoming converted into an ill-defined fibrous sheet. On the contrary, even after 485 days' denervation the general form of each muscle was fully retained, despite a reduction in size and weight, and each could be readily identified and easily removed. The muscles shortened appreciably on removal and it was necessary to stretch them gently on a card in order to restore them to their original length. This shortening, together with the fibrillation to be described, indicated that contractile tissue had survived 485 days' denervation. The characteristic features which distinguished the denervated from the corresponding non-denervated muscle were a change in colour, a reduction in size and weight, and the presence of fibrillation.

Colour Change.-The denervated muscle was distinctly paler, but despite this it still retained a colour and texture which identified it as muscle tissue. There was never any suggestion of a yellowish or translucent appearance.

Reduction in Size and Weight.-The most conspicuous change was a reduction in size and weight. The time course of this reduction with increasing periods of denervation is illustrated in Fig. 1, where

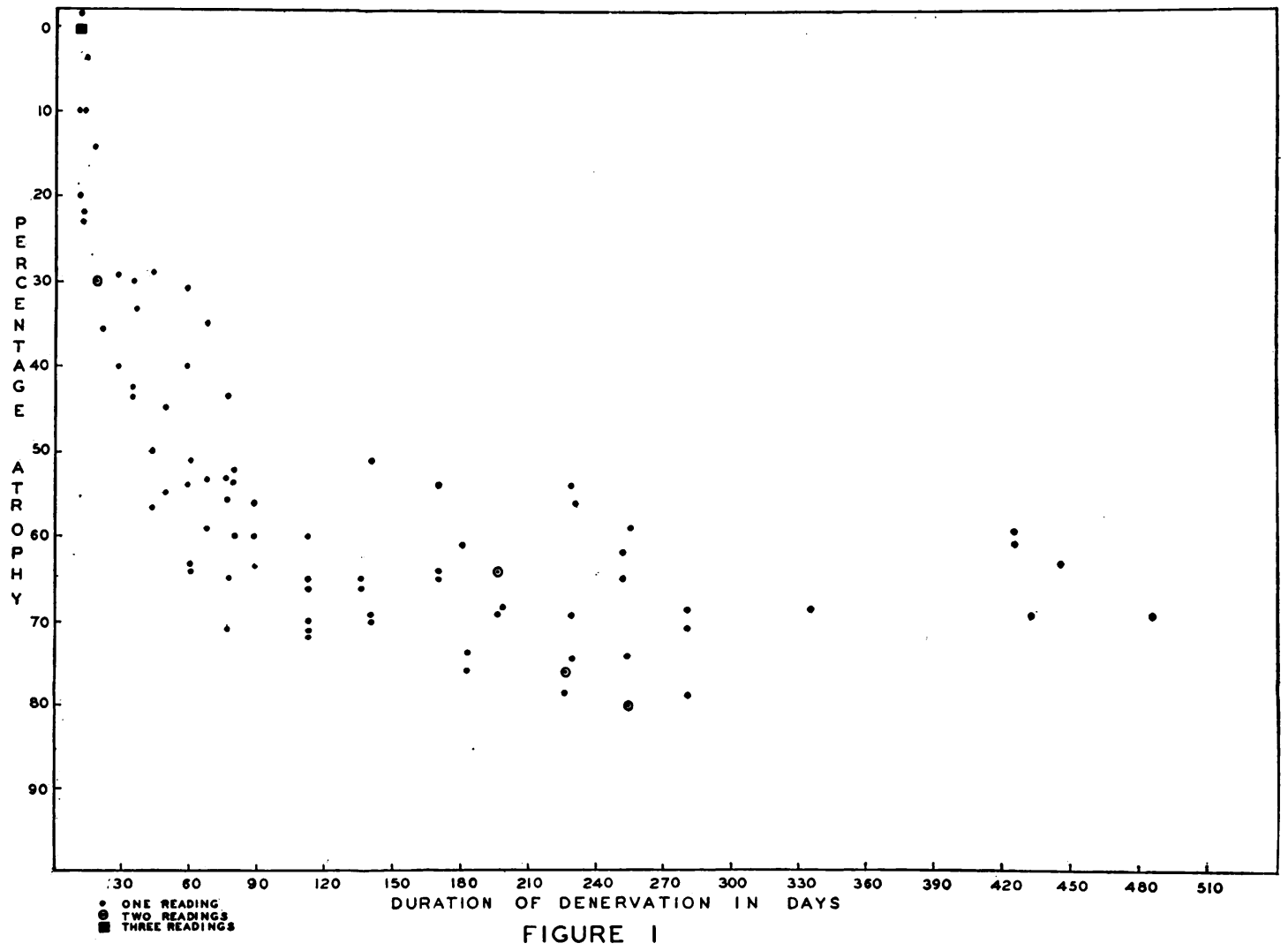




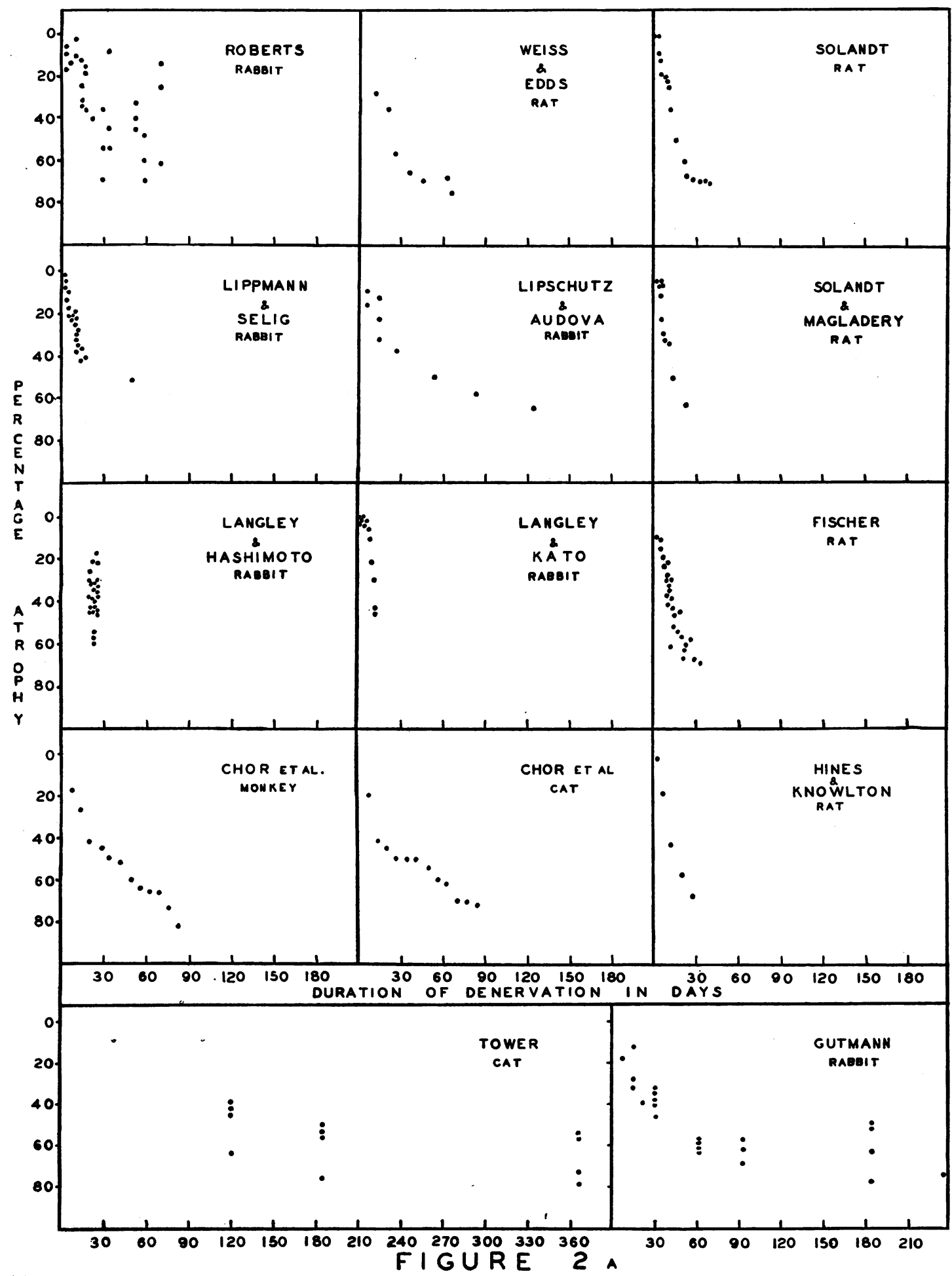




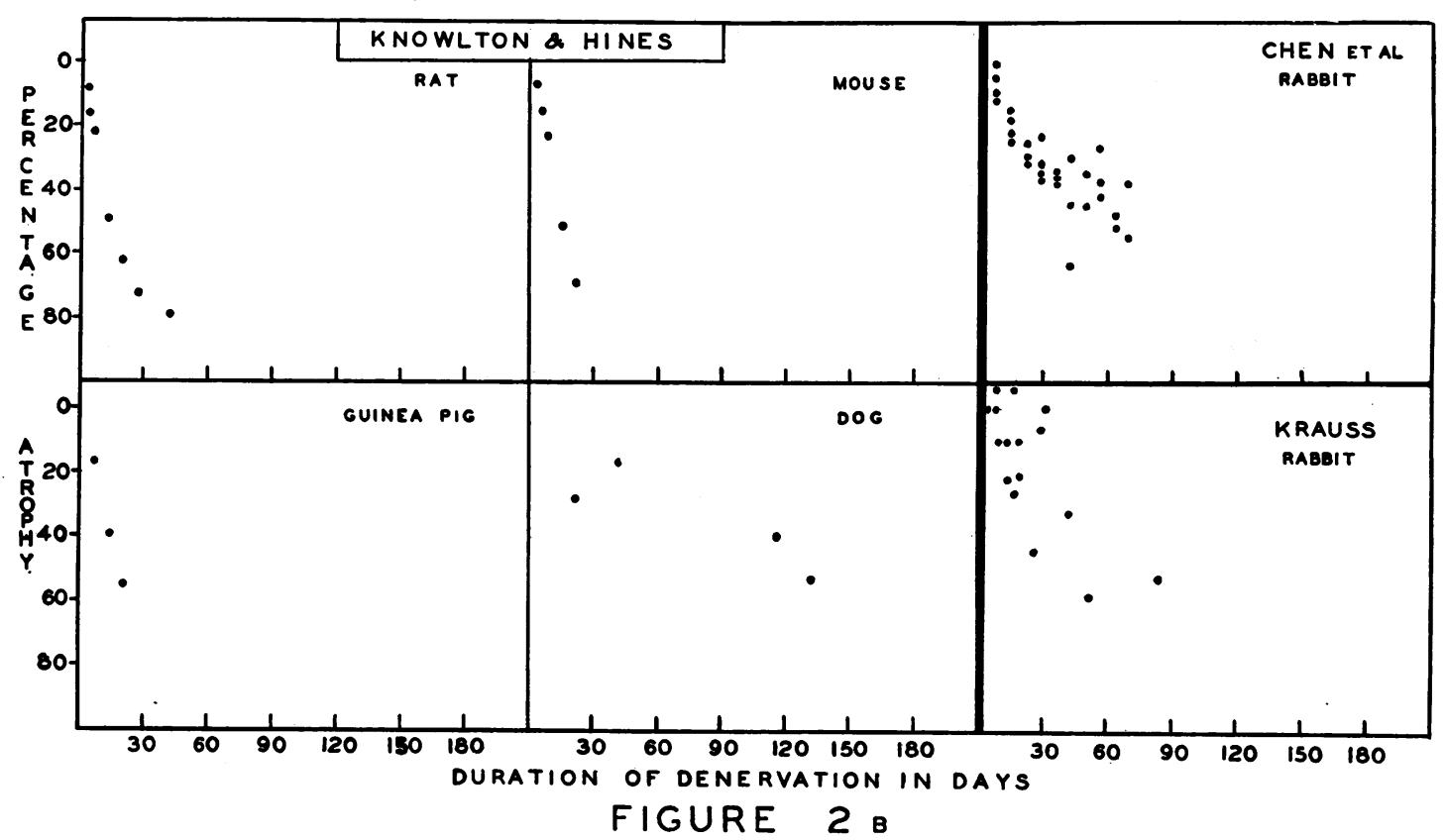

the percentage loss of weight has been plotted against the duration of denervation in days. There was a rapid initial loss of weight, the muscle sustaining a $30 \%$ loss in 29 days which had increased to 50 to $60 \%$ by 60 days. The process then slowed and a relatively stable state was reached somewhere about 120 days from which time onwards the weight loss varied between 60 and $80 \%$.

The curves giving the rate of denervation atrophy, which have been obtained by other workers, have been included for comparison with our own; collectively they cover a variety of muscles and animals (Figs. $2 a$ and $b$ ). Where a graph was not provided one has been constructed from data contained in their texts. The graph based on Tower's work (1935) is of rather doubtful significance. It will be seen that the period covered by her experiment was extensive (12 months) but that the number of points is very small. In her original work Tower did not construct a graph but included her results for weight loss in a table. On examination it was found that there was a marked discrepancy between the weights given for the muscles and the percentage loss so calculated. It is presumed that this discrepancy is typographical in origin and the error lies in the percentages given rather than the weights. Acting on this assumption new percentages have been calculated and these results used in the graph given in Fig. 2. With the exception of Tower (1935) and Gutmann (1948), other workers have confined their attention to the first few months of denervation.
Knowlton and Hines (1936) have stated :

"It does seem, however, as if the specific denervation atrophy rate, ' $k$ ', is an hereditary characteristic of a species, possibly related to the genetic factors associated with determinators of growth rate."

Though the graphs suggest a more rapid loss in the initial stages for some animals, it is difficult to be decisive on this point because the construction of a graph is complicated by such factors as lateral differences in the weight of corresponding muscles, possible differences in the conduct of the experiments, the range of variation in percentage atrophy seen in muscles denervated for the same period, and the limited observations of a number of investigators. The general nature of the curves, however, appears to te substantially the same over this initial period of denervation regardless of the animal employed. Thus there is general agreement concerning the marked loss of weight within the first two months of denervation (Table III). The most rapid and severe atrophy, namely one of $72 \%$ in four weeks in the rat, has been described by Hines and Knowlton (1933). The flattening in the curve, which is just appearing in the graphs confined to the early stages, was sustained in the opossum for 485 days. Gutmann (1948) who followed the process for eight months in the rabbit has reported that "the loss of weight between the third and sixth months appears to be almost insignificant, suggesting little change in the muscle during this period"; the maximum weight loss observed by him was $77 \%$ in one specimen at six months. 
TABLE III

DATA OF OTHER AUTHORS RELATING TO THE PERCENTAGE ATROPHY OF MUSCLES OCCURRING WITHIN THE FIRST TWO MONTHS OF DENERVATION

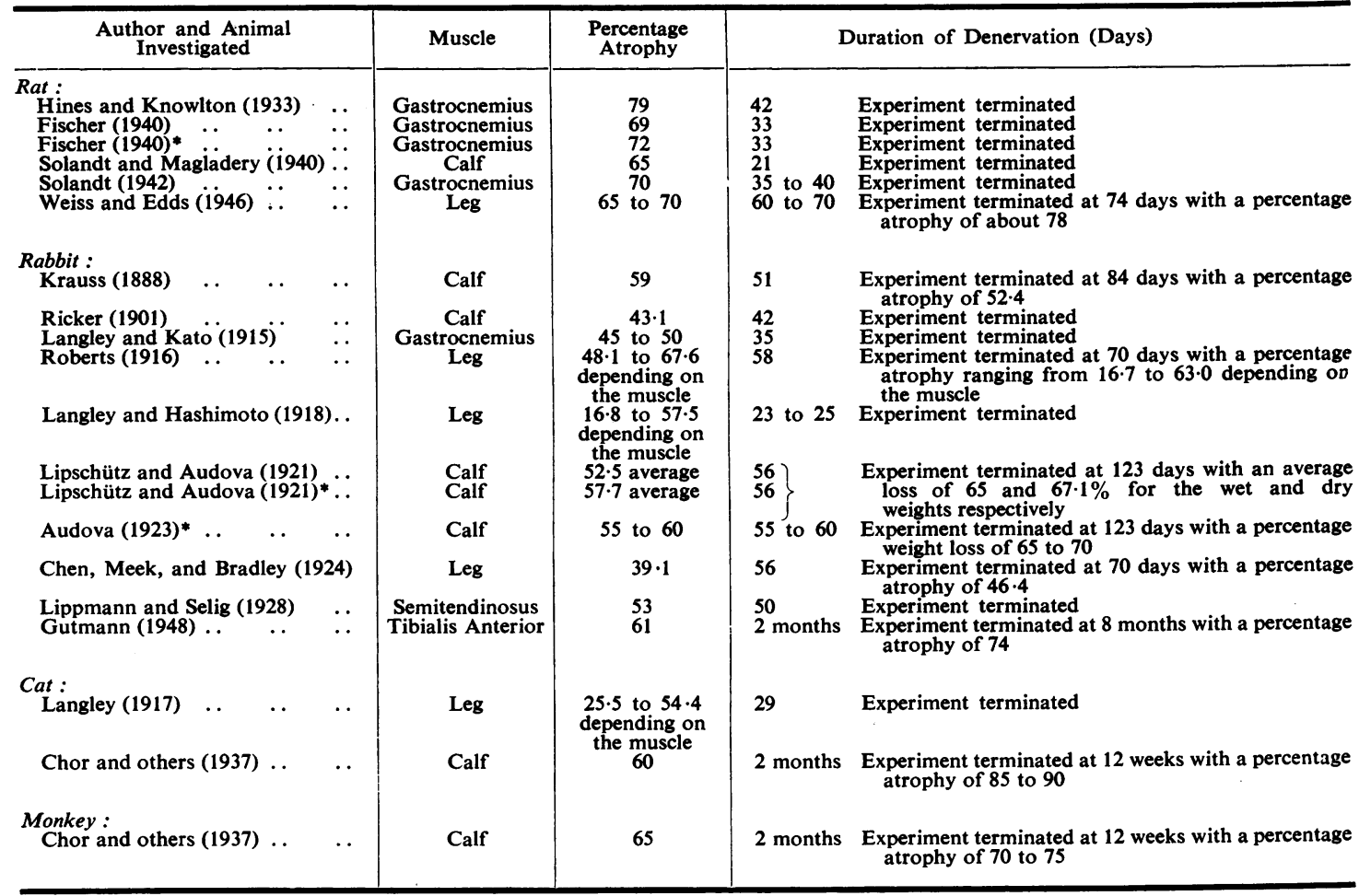

* Based on weights of the dried muscle.

Though the curve of atrophy was substantially the same for all three muscles we investigated, differences in the extent of the atrophy of different muscles have been reported (Roberts, 1916; Langley, 1917 ; Langley and Hashimoto, 1918 ; Tower, 1939; and Altschul, 1942). Roberts attributed the greater atrophy of the gastrocnemius compared with the tibialis anterior in his rabbit material to the stretching of the former and the relaxation of the latter. According to Langley and Hashimoto the chief factor in this difference is the "varying nature of the muscle fibres". They did not favour the theory that differences in the degree of tension are sufficient to account for the differences which occur in the extent of the atrophy in different muscles and reported that some of their experiments, though they did not give definite results, " tend to show that with nearly complete relaxation there is at least as much atrophy as with moderate intermittent stretching ". The overall picture of atrophy was substantially the same for all three muscles studied by us despite the fact that two were maintained in an almost continuous state of stretch while the third was subjected to alternate relaxation and stretching. Unfortunately other workers have failed to define the position of the paralysed muscles in their experiments. The available information concerning the differences in the rate and extent of the atrophy reported for some muscles and whether or not the position of the muscles contributes to this difference, hardly justifies any definite conclusions.

Fibrillation.-Fibrillation appeared between the ninth and sixteenth days and was observed at 34 , $60,68,76,78,89,135,185,254,335,426,444$, and 485 days. It could not be detected in several specimens despite a careful search though we were compelled to rely on inspection of the muscle to establish its presence. The fibrillation, however, may be so fine as to escape detection by this simple procedure. Though electrical methods for recording fibrillation are more sensitive and reliable than mere observation, these methods were not available to us. The fibrillation was best seen, and only became apparent in most cases, after the muscle had been exposed by reflecting the deep fascia; 
it could sometimes be seen through the fascia but was never visible through the shaven skin. The onset and duration of fibrillation reported by others are given in Table IV. inferred on more than one occasion (Chen, Meek, and Bradley, 1924; Tower, 1935 and 1939 ; Chor, Dolkart, and Davenport, 1937 ; Solandt, 1942 ; Gutmann and Young, 1944 ; Weiss and Edds, 1946).

TABLE IV

ONSET AND DURATION OF FIBRILLATION

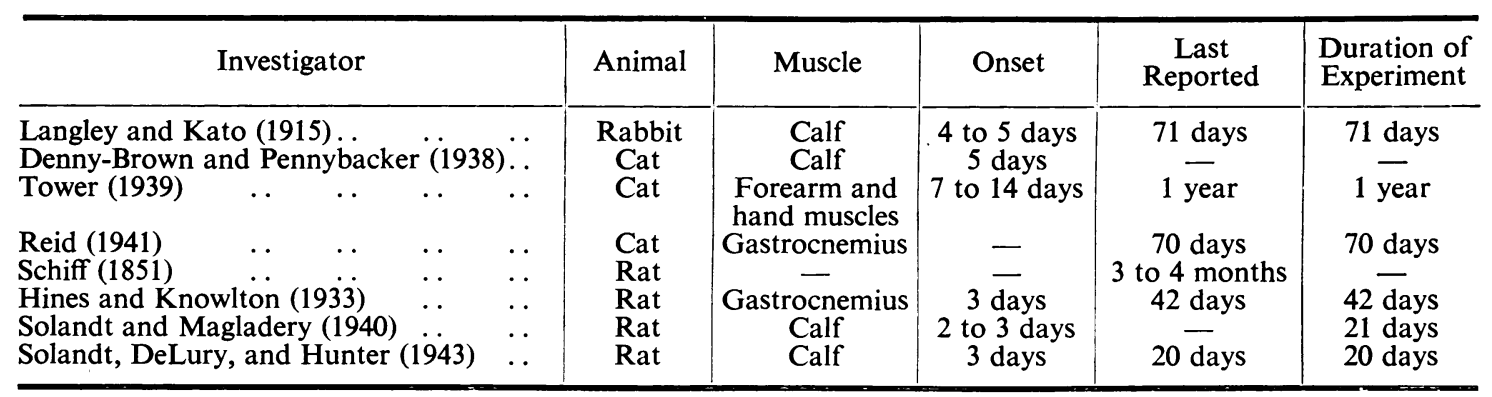

As in Langley's (1917) experiments fibrillation was accentuated by warmth and could no longer be seen when the muscle was cooled. Tower (1939) reported that it ceased under tension though she stated that the cessation might be apparent rather than real. Like Solandt and Magladery (1940), we found that light tension was without effect. The former demonstrated this by electrical methods and concluded that tension has a masking effect by tensing the fascia which renders invisible the fine rippling movement.

The fibrillation did not appear to be as marked in the later experiments after the weight loss became constant but, in the absence of any precise recordings by reliable methods, this observation must be regarded only as an impression.

The fact that obvious fibrillation was observed 485 days after denervation is consistent with observations on human material where fibrillation in the tongue has been known to persist for several years (five in our experience) after facio-hypoglossal anastomosis has been performed to compensate for irreparable injury of the facial nerve. Active fibrillation was observed in Tower's material after one year's denervation.

\section{Microscopic Features of the Denervated Muscle}

It is of particular interest to enquire into the nature of the residual tissue when no further significant weight loss occurs, in view of statements to the effect that 10 to $25 \%$ of a muscle is connective tissue (Knowlton and Hines, 1936; Weiss and Edds, 1946) which suggests the complete destruction and elimination of the contractile constituents. That this is the fate of muscle which has suffered continued denervation has been expressed or

\section{The Reaction of the Extrafusal Fibre to Denervation} (Figs. 3 to 8)

Calibre.-The earliest and most characteristic change in the morphology of the denervated fibre involved a loss of sarcoplasm and a reduction in its calibre. This was generalized throughout the muscle and appeared to proceed at about the same rate in the different regions examined. The fibres atrophied rapidly in the initial stages so that at 60 days the average fibre cross-sectional area was reduced by $70 \%$. The process then slowed appreciably so that approximately 60 days later (i.e. about 120 days after denervation) the atrophy had advanced only a further $10 \%$. From this time onwards the atrophy, with two exceptions, varied between 80 and $90 \%$ and over this range there was no constant relationship between the amount of the atrophy and the duration of the denervation. The course of the fibre atrophy was the same in all three muscles studied. Details of the extent and time course of this atrophy are provided in Table $\mathrm{V}$ and in the graph illustrated in Fig. 9, in which the percentage reduction in the average cross-sectional area of the fibres has been plotted against the duration of denervation. Though the curve outlining the rate and extent of the fibre atrophy follows the same general form as that representing the loss in weight of the entire muscle, a comparison of the two shows that the reduction in the contractile component exceeds the weight loss of the entire muscle at all stages of denervation. From this it is apparent that the fibres suffer more severely than the loss in weight of the muscle indicates so that the calibre of the fibres provides a more accurate measure of the reaction to denervation than does the weight of the muscle. The difference 


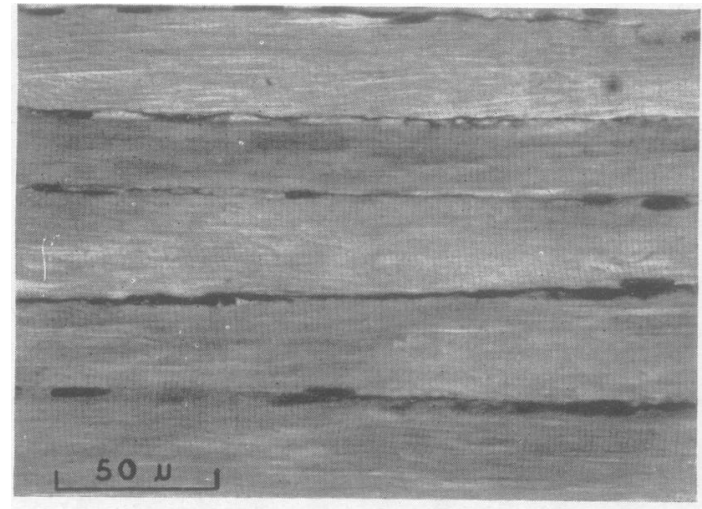

FIG. 3a

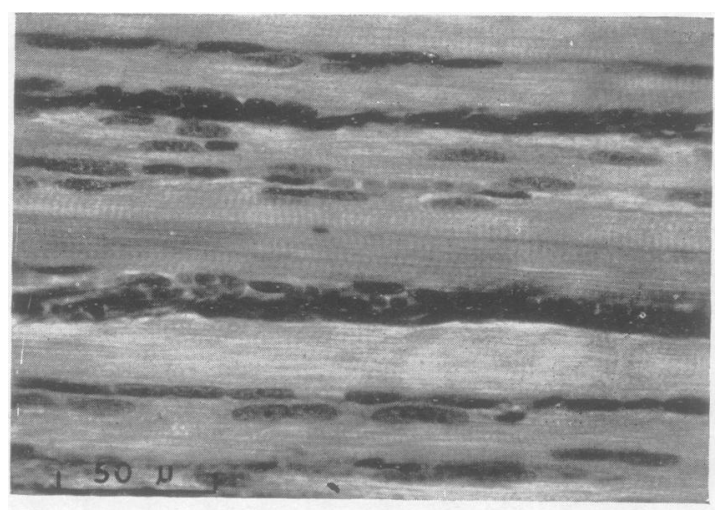

FIG. $4 \mathrm{a}$

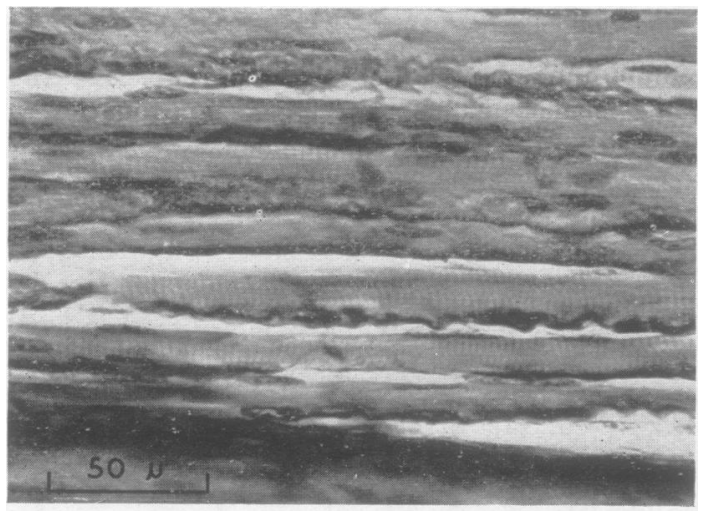

FIG. 5a

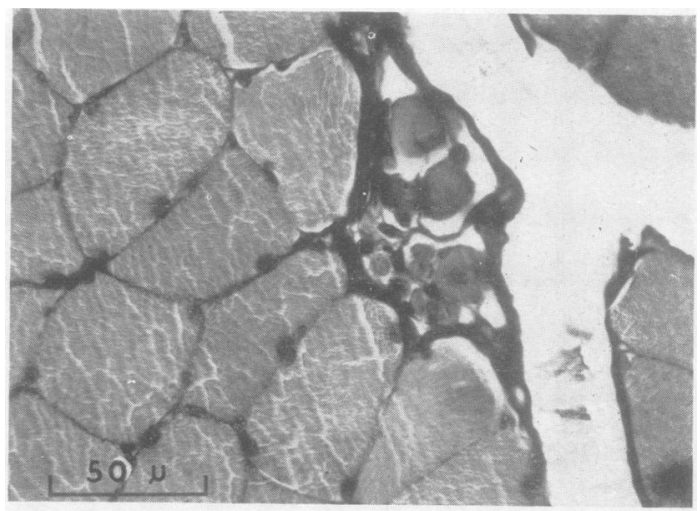

FiG. 3b

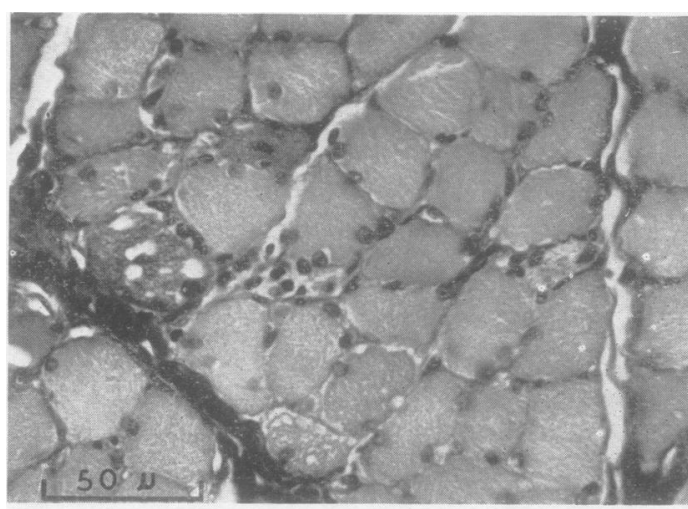

FIG. 4b

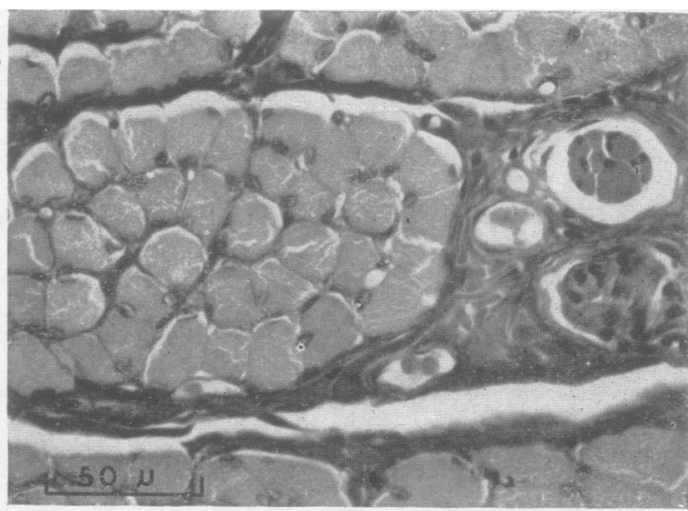

FIG. 5b

FIG. $3(a$ and $b$ ).-Transverse and longitudinal sections of normal pronator teres muscle.

Fig. $4(a$ and $b$ ).-Pronator teres. Duration of denervation 49 days. Percentage muscle atrophy 55. Percentage fibre atrophy 67.

Fig. $5(a$ and $b$ ).-Pronator teres. Duration of denervation 112 days. Percentage muscle atrophy 72. Percentage fibre atrophy 82 . 


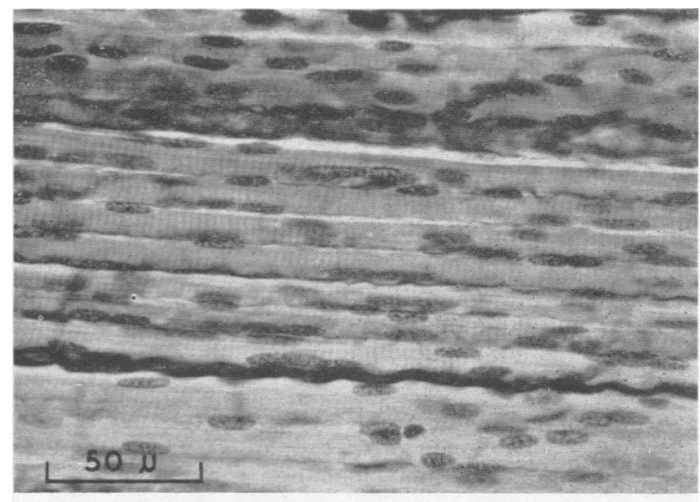

FIG. 6a

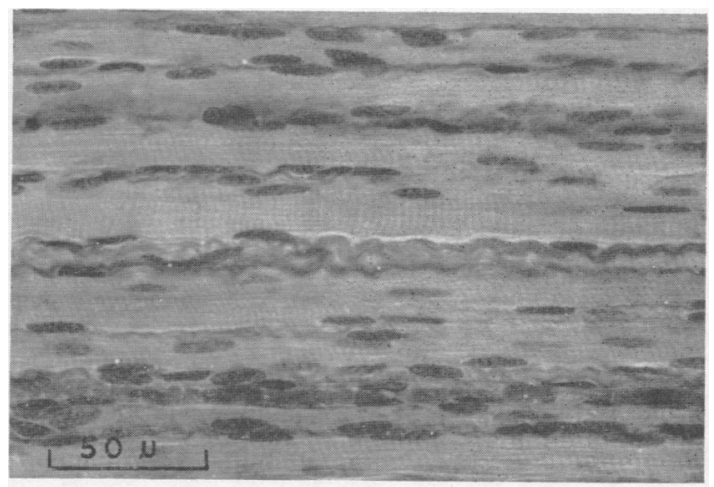

FIG. 7a

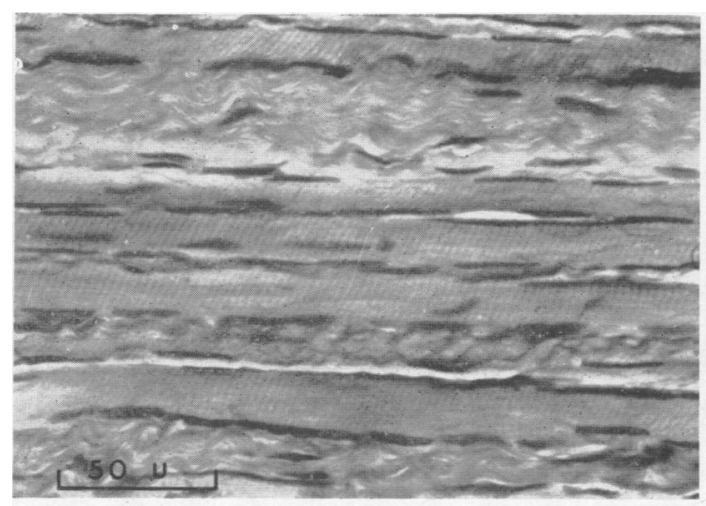

FIG. $8 \mathrm{a}$

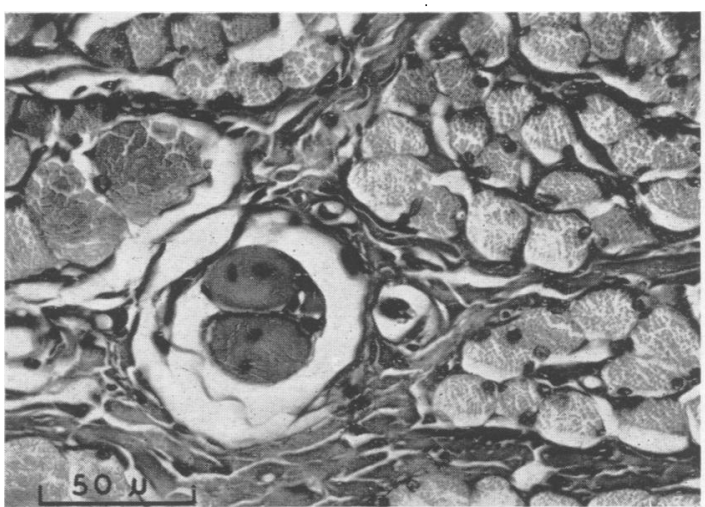

FIG. $6 b$

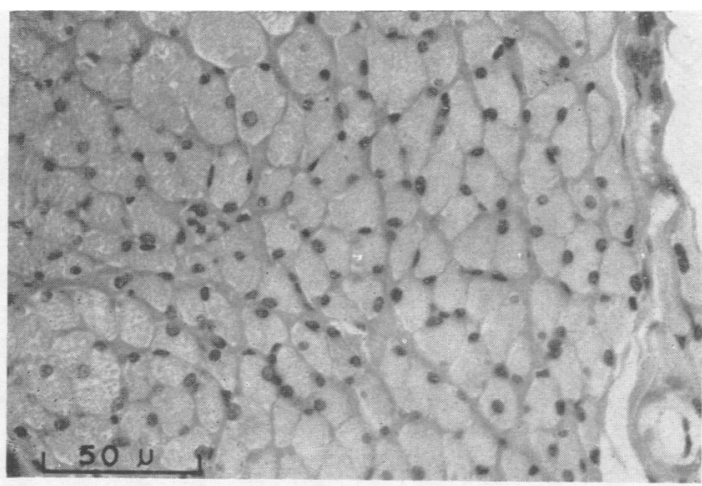

FIG. $7 b$.

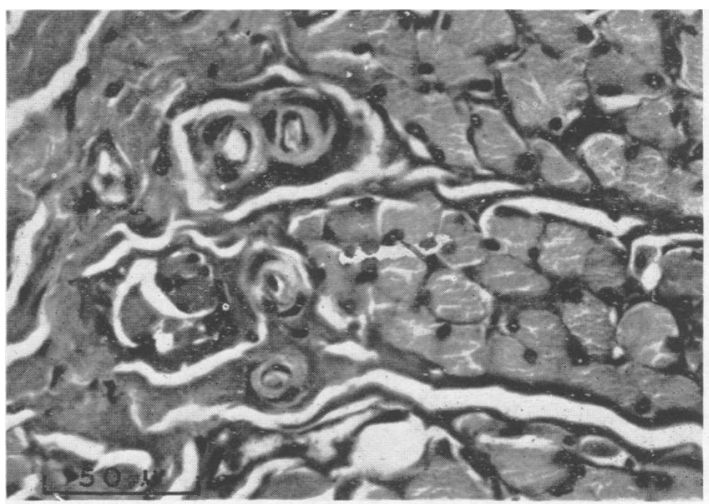

Fig. 8b

FIG. $6(a$ and $b$ ).-Pronator teres. Duration of denervation 229 days. Percentage muscle atrophy 74. Percentage fibre atrophy 87.

Fig. $7(a$ and $b$ ).-Pronator teres. Duration of denervation 280 days. Percentage muscle atrophy 78. Percentage fibre atrophy 93.

Fig. 8. ( $a$ and $b$ )-Flexor carpi ulnaris. Duration of denervation 485 days. Percentage muscle atrophy 69. Percentage fibre atrophy 91 . 
TABLE V

RELATIONSHIP BETWEEN PERCENTAGE ATROPHY OF MUSCLE AND THAT OF ITS COMPONENT FIBRES WITH DIFFERENT PERIODS OF DENERVATION

\begin{tabular}{|c|c|c|c|}
\hline $\begin{array}{c}\text { Duration of } \\
\text { Denervation (Days) }\end{array}$ & Muscle & $\begin{array}{l}\text { Percentage Loss } \\
\text { of Weight }\end{array}$ & $\begin{array}{l}\text { Percentage Decrease } \\
\text { in Fibre Size }\end{array}$ \\
\hline $\begin{array}{r}9 \\
16 \\
21 \\
29 \\
49 \\
58 \\
76 \\
76 \\
89 \\
112 \\
112 \\
135 \\
140 \\
185 \\
196 \\
198 \\
224 \\
229 \\
252 \\
254 \\
280 \\
485\end{array}$ & $\begin{array}{l}\text { Pronator teres } \\
\text { Pronator teres } \\
\text { Flexor carpi ulnaris } \\
\text { Pronator teres } \\
\text { Pronator teres } \\
\text { Flexor carpi ulnaris } \\
\text { Pronator teres } \\
\text { Pronator teres } \\
\text { Pronator teres } \\
\text { Flexor carpi ulnaris } \\
\text { Pronator teres } \\
\text { Flexor carpi ulnaris } \\
\text { Pronator teres } \\
\text { Pronator teres } \\
\text { Pronator teres } \\
\text { Flexor carpi ulnaris } \\
\text { Pronator teres } \\
\text { Pronator teres } \\
\text { Pronator teres } \\
\text { Pronator teres } \\
\text { Pronator teres } \\
\text { Flexor carpi ulnaris }\end{array}$ & $\begin{array}{l}10 \\
30 \\
36 \\
40 \\
55 \\
31 \\
71 \\
56 \\
63 \\
60 \\
72 \\
63 \\
69 \\
73 \\
69 \\
68 \\
76 \\
74 \\
62 \\
80 \\
78 \\
69\end{array}$ & $\begin{array}{l}37 \\
37 \\
14 \\
67 \\
67 \\
71 \\
76 \\
33 \\
81 \\
81 \\
82 \\
86 \\
81 \\
79 \\
88 \\
89 \\
95 \\
87 \\
74 \\
97 \\
93 \\
91\end{array}$ \\
\hline
\end{tabular}

between the weight loss and reduction in fibre calibre is to be accounted for by an increase in the amount of connective tissue which compensates in some measure for the greater atrophy of the fibre. This finding is contrary to that reported by

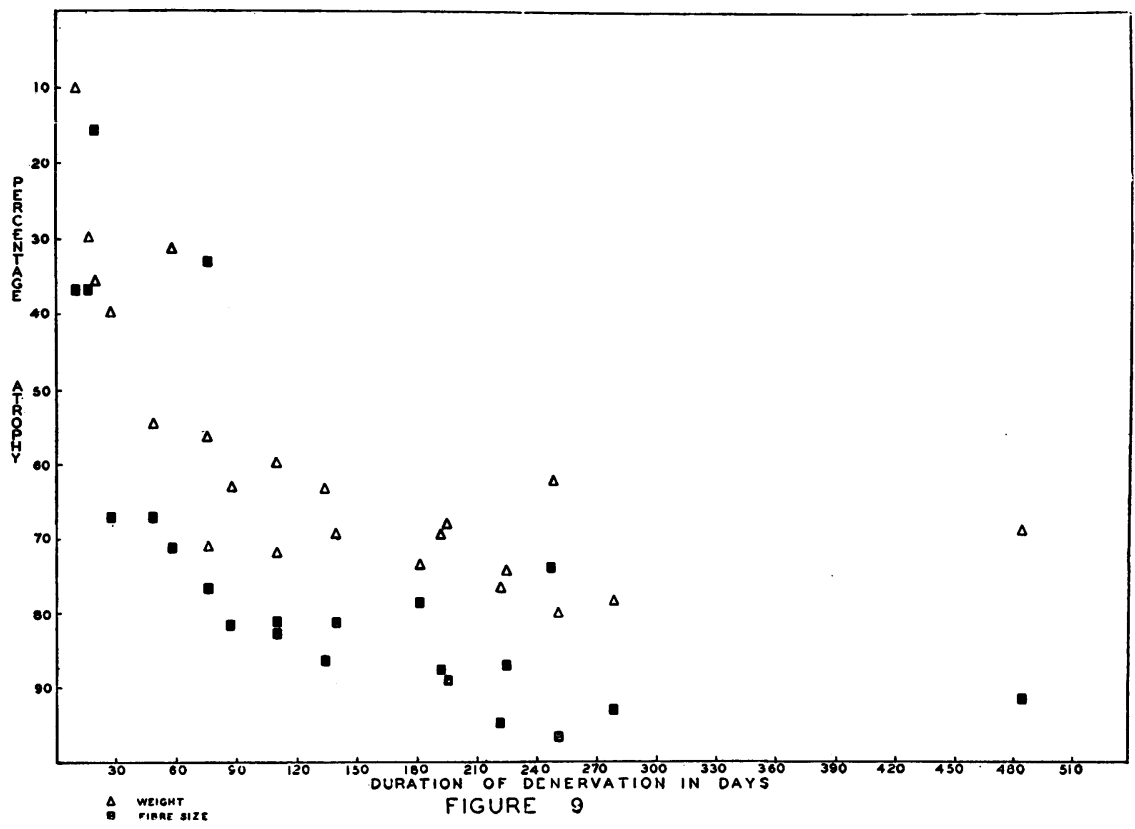

Gutmann (1948) who has claimed, with reference to weight loss and fibre atrophy, that "there is aㄹ quicker diminution in weight at first, followed by parallel changes thereafter".

Bowden and Gutmann (1944) observed " noo profound changes" in human denervated muscle within the first three months though the atrophy wasconsiderable from four months onwards. In Gutmann and Young's (1944) rabbit material the atrophy was " not yet extreme" at five months and the fibres were " not yet excessively atrophied at seven months". Two months later some fibres were approaching the extreme condition of atrophy but after eleven months' denervation the histological picture was one of masses of fat cells from which 
fibres had completely disappeared while many others were approaching the final stage of atrophy. Tower (1935) found the diameter of the fibres unaltered at two weeks while at the end of a month the atrophy was apparent but not conspicuous. A month later atrophy was far advanced with an average reduction in fibre size of one-third to onehalf. From this time onwards more severe changes involved the fibres. Though these investigators did not measure the fibre atrophy their data suggest that the fibres in the opossum atrophy more rapidly than those in the other mammalian material studied. However Gutmann (1948) has published data based on a metrical analysis of fibre atrophy in the rabbit which are consistent with those reported by us, while Willard and Grau (1924) observed a progressive decrease in fibre diameter of up to $68 \%$ in 63 days.

Subsarcolemmal Nuclei.-The nuclei became larger and more oval between the ninth and the sixteenth day and persisted in this form until fibre atrophy was well advanced when the majority had resumed their original elongated form. This sequence of changes has been observed by most previous investigators (Krauss, 1888 ; Tower, 1935 and 1939 ; Bowden and Gutmann, 1944 ; and Altschul, 1948) though Willard and Grau (1924) reported an early reduction in nuclear diameter in their mouse material. Tower $(1935,1939)$ represents the nuclei as " sometimes bloated to an extraordinary degree" and creates the impression that this is a prelude to degeneration; we did not see such bloated forms. Altschul (1948) attributes the increase in volume to a decrease in interstitial pressure and a relative increase in nuclear pressure. We are unable to account for the enlargement though the appearance of the nucleus is highly suggestive of activity rather than of degeneration. The elongated form began to reappear between 90 and 120 days, when the fibre atrophy was reaching its peak and the histological picture suggested that the nuclear elongation was the result of compression caused by the shrinkage of the fibre. Tower (1935) and Bowden and Gutmann (1944) have also described the reappearance of elongated nuclei in their material from the fourth month of denervation onwards though we never saw nuclei resembling "tendon nuclei" as reported by Tower.

Bowden and Gutmann (1944) reported an increase in the number of nucleoli between the fourth month and a year and thereafter a decrease while Tower (1935) described a reduction as early as the second week which persisted. We were unable to detect any changes in the nucleoli which were not also observed in the control specimens.

Though some nuclei were centrally placed in the fibres from the sixteenth day onwards the majority retained their original peripheral position. A central position was not so common in this material and in that described by Krauss (1888, rabbit) as was observed by Tower (1935, cat), Gutmann and Young (1944, rabbit) and Bowden and Gutmann (1944, man). However the gross atrophy of the fibre results in the nuclei occupying much more of the cross-sectional area of the fibre and this often creates the appearance of a centrally placed nucleus, particularly when the latter is enlarged.

Nuclei were never seen in the process of division, either mitotically or amitotically. Though the tissue presented an appearance which was highly suggestive of nuclear proliferation, nuclear counts in transverse and longitudinal preparations failed, with two exceptions, to confirm this. On the contrary the counts gave values which were within the range of variation presented by the normal control specimens. The two exceptions were specimens which had been denervated for 185 and 280 days respectively and these showed a nuclear proliferation of approximately $50 \%$. Willard and Grau (1924) were also unable to detect a numerical change in the nuclei of mouse muscle over the 63-day period of denervation studied by them but a numerical increase has been reported by others (Krauss, 1888 ; Stier, 1896 ; Ricker and Ellenbeck, 1899 ; Jamin, 1904 ; Schmidtmann, 1916 ; Tower, 1935 ; Chor and others, 1937 ; Altschul, 1942 ; and Bowden and Gutmann, 1944). Chor and others (1937) alone claim to have seen mitosis.

Confusion still persists concerning the question of nuclear degeneration. Tower (1935) reported fragmentation from one month onwards in the cat, the destructive process proceeding steadily after six months to eliminate nuclei from the extrafusal fibres for " from this time forward their numbers obviously decline". Stier (1896) also reported the destruction of nuclei over the three and a half months' period of his investigation. Bowden and Gutmann (1944), however, saw nuclear degeneration in human material only after three years. There was no evidence of degeneration within the time limits covered by the present enquiry, nor did the counts suggest any decline in the number of nuclear elements at the conclusion of the investigation.

Striations.-It is not always possible to obtain consistently uniform staining of the striations even in normal fibres, and this makes it difficult to determine whether their absence or fading in denervated material is to be attributed to the denervation or to vagaries in the staining. The transverse and longitudinal striations, however, were well preserved and intensely stained in most 
fibres throughout the period of denervation covered by the enquiry. The distance from the centre of one anisotropic disc to another remained unchanged, but from the sixteenth day onwards these discs appeared to be thicker and less sharply defined than those from the corresponding muscle from the control side and Hensen's line was more difficult to detect and often was absent.

Strümpel (1894), Stier (1896), Jamin (1904), and Willard and Grau (1924) did not observe any change in the fibrillæ in their material. Bowden and Gutmann (1944) reported that the striations were more commonly absent after four months' denervation than in normal muscle but that even after three years' denervation they " may still be intact in the thinnest fibres". Tower's $(1935,1939)$ statements on this subject are somewhat conflicting. In one section she states that " all through the early stages and to the end of a year the cross and longitudinal striated structure survives in remarkably good order" but elsewhere we read that " after a month or two the cross striation is clearly faded becoming finally scarcely more than a shadow", and at one year "they are excessively faded and over large areas even seemingly wanting" but "where they are visible alignment is remarkably well preserved ". Though degenerating changes have also been described by others (Erb, 1868 and 1869 ; Krauss, 1888 ; Ricker and Ellenbeck, 1899) there is no doubt that many denervated fibres do retain their characteristic striated appearance despite denervation for over a year and the gross atrophy which this induces.

End Plates.-We are unable to state whether or not there was any reduction in the number of plates but the examination of large numbers of sections indicated that surviving fibres still carry an end plate regardless of the period of denervation. The plates however became more difficult to detect as the atrophy of the fibre reached maximum values since they then extended across the full width of the fibre so that great care was required to distinguish their nuclei, which were now more crowded, from other nuclear aggregations within the fibre. The end plate nuclei did not undergo the enlargement observed in the case of the subsarcolemmal nuclei but remained unchanged, nor were they observed to proliferate. Bowden and Gutmann (1944) could also identify the end plates by their characteristic arrangement after a year's denervation; thereafter fibre atrophy made their identification difficult. Gutmann and Young (1944) were unable to find any " proper evidence to show that end plates atrophy" and concluded that they remain with relatively little change on most of the fibres for a considerable period (at least nine months) of atrophy; some were observed which persisted for 17 months. They were careful to point out the impracticability, in the later stages of atrophy, of accurately determining whether there is a gradual reduction in the number of nuclei or other signs of atrophy and correctly emphasized that the persistence of some plates for a very long time does not prove that others have not disappeared.

These findings are not in harmony with those of Tower (1935 and 1939) and Chor and others (1937). According to the former the end plate cytoplasm had disappeared completely by six months at which time the associated nuclei could not be distinguished from subsarcolemmal nuclei, while the latter state that "by the end of one week, only occasional remnants may be seen scattered throughout the denervated muscle ... a and are rarely observed after two weeks".

Muscle Fibre Degeneration.-The only occasion when degenerating fibres were seen was in a muscle which had been denervated for 49 days. Approximately a dozen scattered fibres were involved. Among them they showed the usual pattern of vacuolation of the sarcoplasm, collapse of the fibre, its disintegration and the associated phagocytic activity which is, presumably, ultimately $\stackrel{\Omega}{\Omega}$ ? followed by connective tissue replacement. A veryo $\vec{D}$ small superficial area of fibrotic dedifferentiation was observed in a specimen of the flexor carpi ulnarise which had been denervated for $\mathbf{4 4 4}$ days.

This almost total absence of degeneration an fibrous tissue transformation is in agreement with the findings of Willard and Grau (1924), Reid (1941), Gutmann and Young (1944), and Bowden and Gutmann (1944). Willard and Grau did not observe any degenerating fibres in mouse muscle over a denervation period of 63 days and Reid had the same experience with cat muscle denervated for six weeks. The changes described by Gutmann and Young were essentially those of atrophy, in which the fibres became reduced to "very narrow strands containing a simple series of nuclei" from which picture they inferred, however, that many muscle fibres would probably finally break up and disappear. Bowden and Gutmann found that " few, if any, muscle fibres have undergone complete disintegration " after three years' denervation. As was the case with our material they could not detect the acute degeneration and fibrotic dedifferentiation which Tower (1935) had found during the first year of denervation in the cat and suggested that this was because perhaps " atrophy is slower in man than in cats and rabbits". Destructive changes appear to have been a characteristic feature in Tower's 
material. These were first encountered at one month as an acute degenerative process which became conspicuous at four months and in the following two months " destroyed large bodies of fibres completely" after which it subsided. At four months a process described by her as fibrotic dedifferentiation made its appearance by which large regions of the muscle became transformed into fibrous tissue. This process increased in severity as the acute degenerative processes subsided, with the result that at one year the characteristic histological picture was the "advancement almost to completion of the dedifferentiation by which fibres which had escaped the earlier acute degenerations were being reduced to the status of connective tissue". Chor and others (1937) have reported " granular and vacuolar degeneration with replacement by fibrous tissue" and Altschul (1942) "metaplasia of muscle fibrils into connective tissue". Such extreme changes were, with the exceptions noted, not seen in the opossum.

\section{The Neuromuscular Spindle}

The intrafusal fibres shared in the atrophic changes involving the extrafusal fibres but not to the same degree. The periaxial space remained patent and well-defined and was not encroached on by connective tissue, while there was little if any thickening of the capsule which did not lose its identity by blending with the surrounding connective tissue. As a result the spindles could be readily identified throughout the period of denervation (Figs. 10-15) and remained a conspicuous feature of the histological preparations. According to Sherrington (1894), Horsley (1897), and Willard and Grau (1924) the spindles retain their characteristic features following denervation. On the other hand Tower (1932 and 1935) has reported that " the spindle fibres share in all the processes of atrophy and degeneration while the periaxial space is encroached on by connective tissue and the capsule becomes thickened and indistinguishably merged with the surrounding connective tissue". As a result the spindles were much less conspicucus at six months and difficult to find six months later when degeneration was well advanced and "the spindles were almost lost in the fibrosing mass that had been muscle" ; Chor and others (1937) also state that " in the late stages, the spindles as well as the extrafusal fibres are replaced by fibrous tissue ". We never saw this picture. Batten (1897) could not detect any "definite atrophy" after three months' denervation but recorded atrophic changes in the spindles of muscles which had been denervated for a year as the result of a brachial plexus injury.
Connective Tissue

The connective tissue was normally disposed in relation to the muscle fibres in the following manner. The entire muscle was surrounded by a layer of condensed areolar connective tissue, the epimysium, from which a large number of fine septa passed into the substance of the muscle. These fine septa divided and anastomosed in an irregular manner so that the muscle fibres were collected into a number of bundles or fasciculi which varied in size and shape and which were enclosed in a thin but welldefined layer of areolar connective tissue, the perimysium. Within each bundle the individual muscle fibres were closely packed together. Each fibre was invested in, and separated from its neighbours, by an exceedingly delicate sheath of connective tissue, the endomysium, which at the periphery of the bundle was continuous with the perimysium. The normal histological picture was such that any increase in connective tissue could be easily recognized.

Following denervation a significant change could not be detected in either the amount or the quality of the connective tissue for 29 days. During this period the essential reaction was one of atrophy of the muscle fibres. Proliferation of connective tissue appeared first in the perimysium and later involved the endomysium while the deposition of new fibrillar material in both zones was always preceded by a marked increase in the number of fibroblasts. This great increase in fibroblasts was, together with the fibre atrophy, the most characteristic feature of the histological picture of denervation. The cellular proliferation in the endomysium which preceded any thickening of this interstitial layer produced large numbers of nuclei which were sandwiched between the still tightly packed muscle fibres. These nuclei were so closely applied to the sarcolemma as to give the impression, which could be dispelled only by careful examination of the tissues, that it was the subsarcolemmal nuclei which were proliferating.

The fibroblastic proliferation which was first evident in the perimysium at 29 days had reached a peak at 89 days. At 49 days there was a tremendous increase in the cellularity of the endomysium and the perimysium (intramuscular septa), in addition to being extremely cellular, was now obviously thickened. At 56 days the thickened perimysium was composed of coarser and more tightly packed fibres which stained more deeply though the tissue continued to be very cellular. At this time the very cellular endomysium was showing the first signs of thickening as the result of fibrillar deposition. At 89 days, when the muscle and fibre atrophy were approaching maximal intensity, the endomysial 


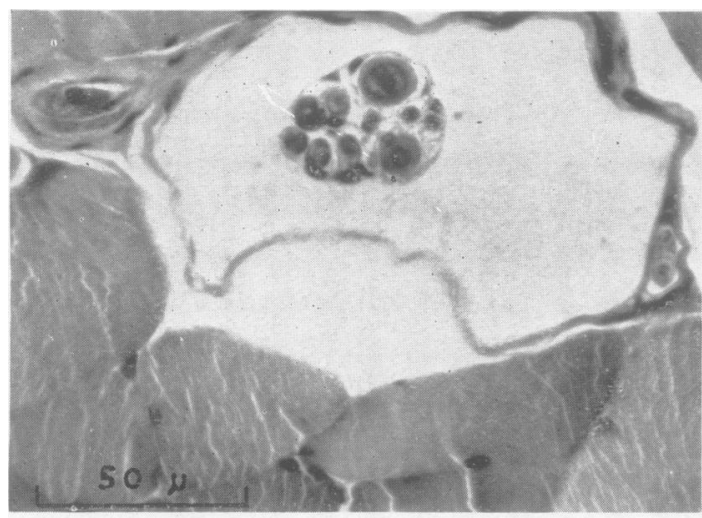

FIG. 10a

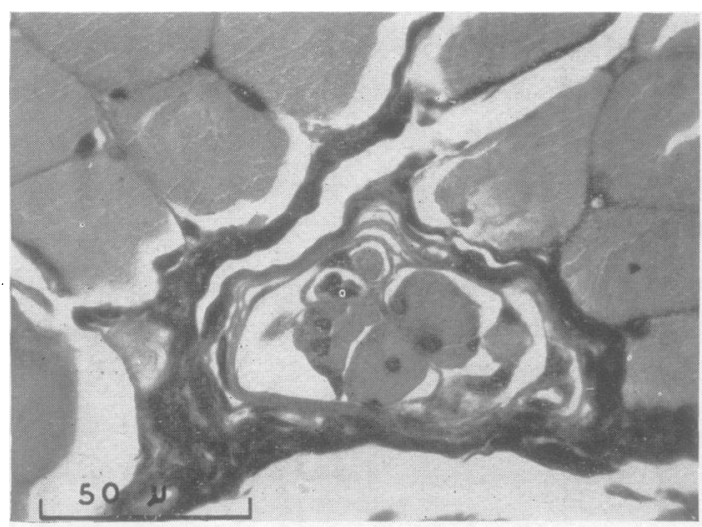

Fig. 10c

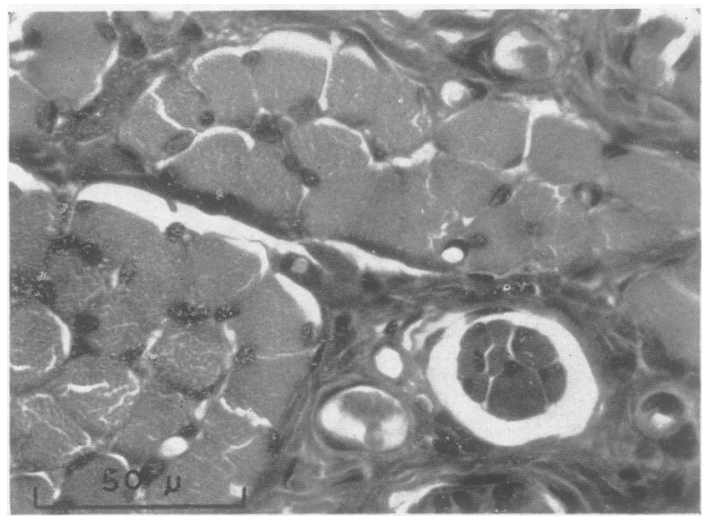

FIG. $11 \mathrm{a}$

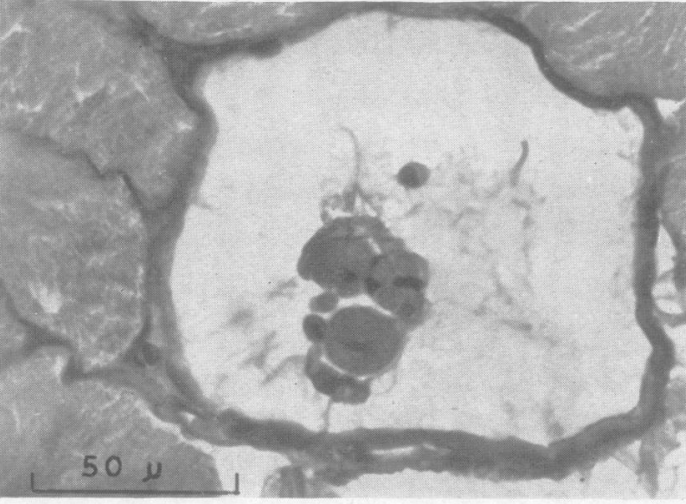

FIG. 10b

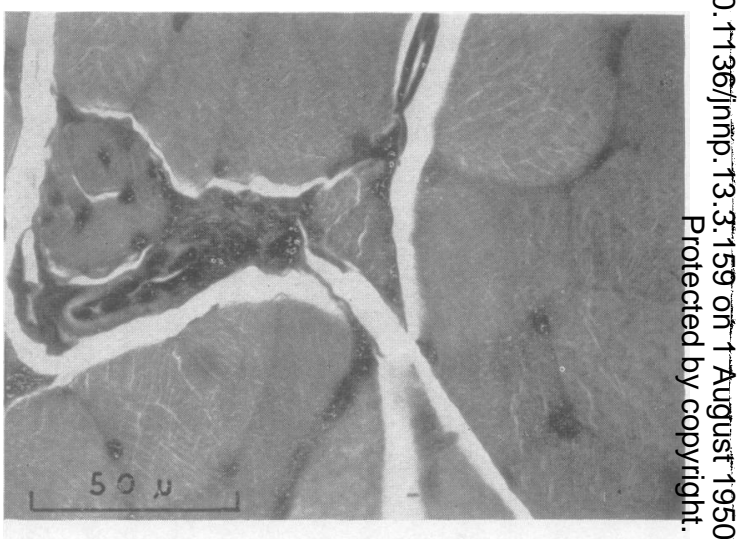

Fig. 10d

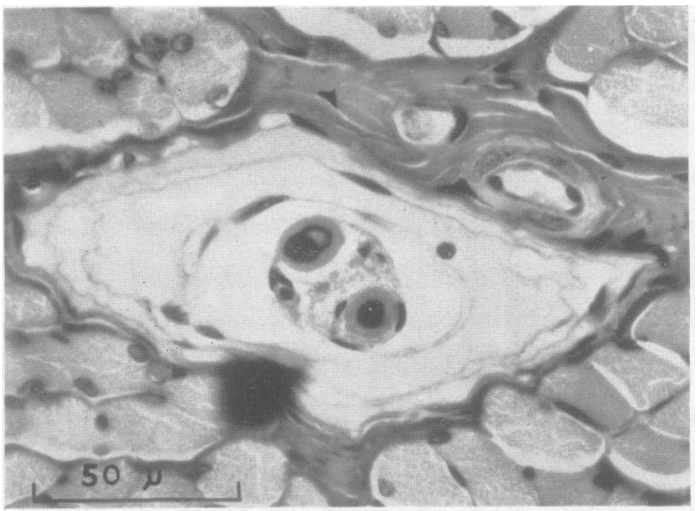

FIG. $11 b$

Fig. 10. $(a, b, c, d)$.-Variations in the appearance of spindles taken from normal control muscles. The subcapsular swelling and a thickened capsule are frequently observed in normally innervated muscles.

FIG. $11(a$ and $b)$.-Pronator teres. Duration of denervation 112 days. Percentage muscle atrophy 72. Two spindles separated by only a few millimetres and taken from the same section; differences in the appearance of two adjacent spindles are apparent. 


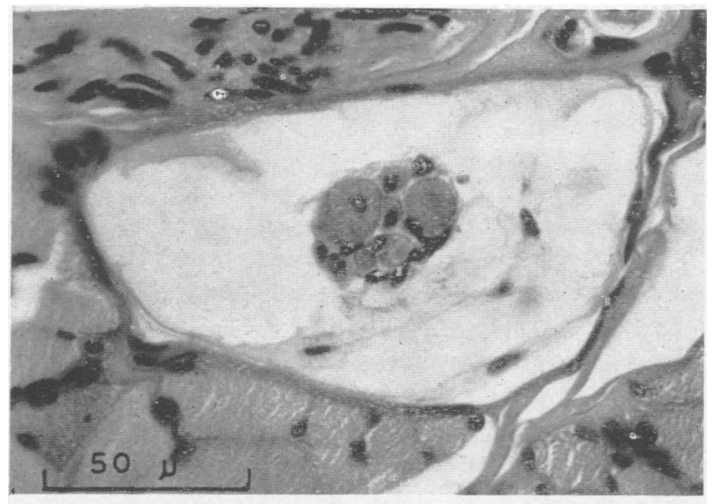

FIG. 12

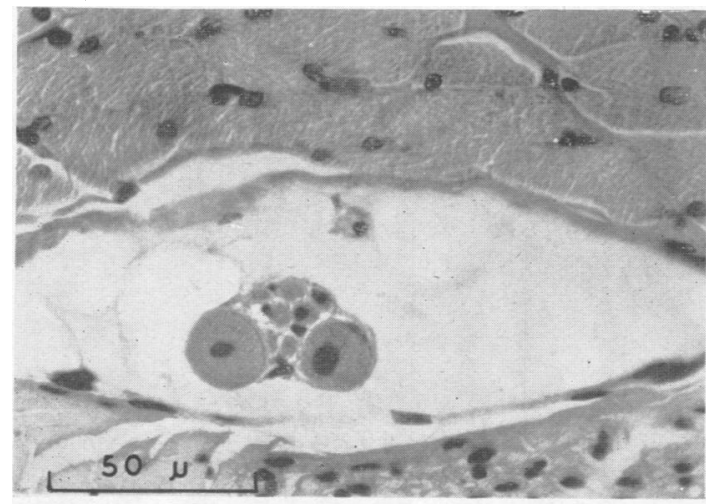

FIG. 14

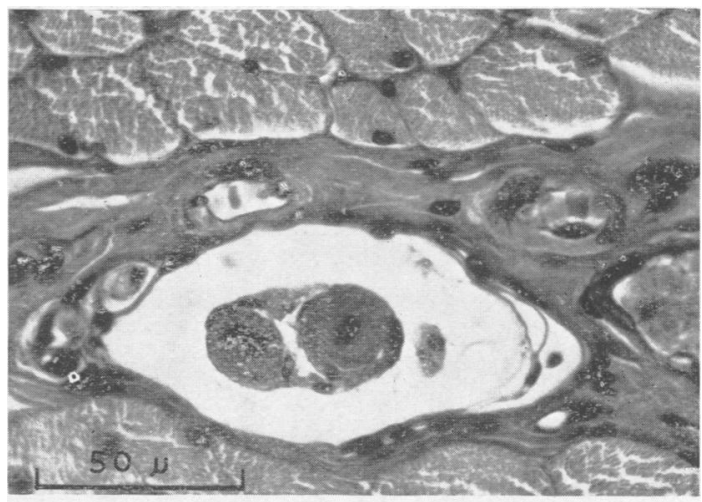

FIG. 13

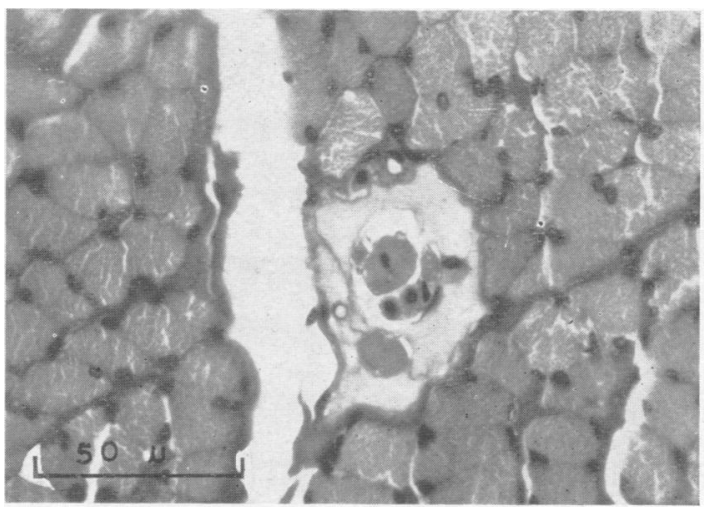

FIG. 15

Fig. 12.-Flexor carpi ulnaris. Duration of denervation 198 days. Percentage muscle atrophy 68. Fig. 13.-Pronator teres. Duration of denervation 229 days. Percentage atrophy 74. Fig. 14.-Pronator teres. Duration of denervation 280 days. Percentage atrophy 78.

Fig. 15.-Flexor carpi ulnaris. Duration of denervation 485 days. Percentage atrophy 69.

thickening had progressed to such a degree that the individual muscle fibres were now separated from one another instead of being packed tightly together. From 89 days onwards there was little further thickening of the endomysium and perimysium. The connective tissue remained extremely cellular as far as the last examination at 485 days, though many of the nuclei in the perimysium had assumed an elongated spindle and pyknotic form at 185 days. Like Bowden and Gutmann (1944) we also observed variations in the amount of connective tissue deposited in specimens denervated for the same time so that the fibrosis is not solely dependent on the latter.

The increase of connective tissue which became conspicuous at two months in the opossum only became so in Bowden and Gutmann's (1944) human material from four months onwards. A "considerable increase in connective tissue" was not recorded by Gutmann and Young (1944, rabbit) until five months, while Willard and Grau (1924) were unable to detect any increase after 63 days' denervation in the mouse. In Tower's material (1935, cat interosseus), however, cell proliferation was evident at two weeks, was still increasing at two months but, unlike in our material, the fibre element was everywhere on the increase at one year.

The connective tissue growth observed in our material did not result in any disorganization of the internal architecture of the muscle. The final picture was one in which the septa outlining the bundles were composed of greater amounts of connective tissue while the intervals between the 
atrophied fibres were occupied by a thickened endomysium. This connective tissue growth was never invasive and at no stage were atrophying muscle fibres replaced by fibrous tissue ; this only occurred in those rare instances when the fibre degenerated. Adipose tissue was observed in some denervated muscles but when present it was unrelated to the duration of denervation. Furthermore the histological picture of the denervated material and the results of a comparison with normal controls supported the belief that the denervation was not responsible for the presence of the fat. Others, however, have reported the appearance of fat as a denervation phenomenon (Krauss, 1888, rabbit ; Grund, 1912, dog ; Audova, 1923, rabbit ; Chor and others, 1937, macaque ; Altschul, 1942, rabbit ; Gutmann and Young, 1944, rabbit; Bowden and Gutmann, 1944, human muscle).

\section{Vascular Changes}

Some arterial thickening was observed in one specimen at 224 days and in another at 485 days but the lumen of the involved vessels was patent. In the remaining specimens there was no trace of obliterating and obliterated vessels nor was there any evidence of vascular stasis. In fact the vascular picture in our material was, with the exceptions noted, well within the range of normal variation.

An early thickening of the arteries of denervated muscles with narrowing of the vessel lumen was described by Kopits (1929), Tower (1935), Chor and others (1937), and Bowden and Gutmann (1944). In Bowden and Gutmann's material these changes became accentuated after one year's denervation so that ultimately arteries were obliterated and many capillaries were "squeezed and stretched out of existence". We are unable to account for the absence of these changes in the opossum.

\section{Intramuscular Nerves}

Degenerating myelin and axoplasm were observed in the nerve fibres at nine days. Most of the endoneurial tubes were almost clear of debris by the twenty-ninth day; an occasional tube in a denervated median nerve still contained some debris at 112 days. Tubal atrophy occurred progressively with increasing periods of denervation but tubes were still visible at the conclusion of the investigation though none exceeded $2 \mu$ in diameter; at this time the pathways of the denervated nerves were still well-delineated.

In Bowden and Gutmann's (1944) human material the original pattern of innervation was maintained as far as the first year though after the fourth month it was difficult to follow individual tubes. Further denervation considerably altered the pattern which underwent a steady distortion and obliteration as the result of the proliferation of connective tissue $\mathbb{D}$ and intraneural fibrosis. A similar picture was observed by Gutmann and Young (1944) in the rabbit.

\section{Discussion}

Studies of the total weight loss and individual fibre atrophy sustained by denervated opossum muscle revealed that the point of maximal intensity for both phenomena was reached about 90 days $\overrightarrow{\vec{F}}$ after denervation. Continued denervation pro- $\vec{\sigma}$ duced little further change, the percentage weight $\frac{C}{0}$ loss remaining between 60 and $80 \%$ and the reduc- $\frac{\bar{c}}{\bar{D}}$. tion in cross-sectional area of the fibres ranging $\widehat{\nabla}$ from 80 to $90 \%$. Degeneration of muscle fibres was rarely observed so that even after 485 days ( ) denervation there was no significant reduction in $\overrightarrow{0}$ their number ; there was, however, a considerable $\vec{\overrightarrow{ }}$ reduction in the amount of their contractile $\vec{\omega}$ substance. The residual tissue after 485 days' denervation therefore contained the original number $\frac{5}{0}$ of fibres and each fibre, though grossly atrophied, $\vec{\omega}$ retained those histological features upon which the $\omega$ identification of striated muscle is based; thes $\vec{v}$ remained clearly defined and well-differentiated 0 from the surrounding tissue, and though the striations were sometimes less prominent and intensely stained than normal, they survived as characteristic feature of the longitudinal section Thus the end result of denervation for this perio $\stackrel{\oplus}{?}$ in the flexores carpi and pronator teres muscles i⿳亠二口犬 the opossum is not complete destruction of the muscle tissue with its replacement by fibrous tissue. As a result of the large amount of material examined it is concluded that the degeneration of muscle fibres is a rare event in muscles which have been denervated for periods up to $\mathbf{4 8 5}$ days. Denervation induced a relative and absolute increase in the connective tissue content of the muscle in the form of a thickening of the perimysium and endomysium, particularly the former. This increase became conspicuous about the forty-ninth day and involved the perimysium first and the endomysium later. A fibroblastic proliferation, which appeared between the sixteenth and twenty-ninth days and reached a peak at 89 days, preceded the deposition of fibrillar material. From 56 days onwards the connective tissue fibres became coarser and more closely packed until a relatively stable state was reached at 89 days. At this time each atrophied fibre was enclosed in, and separated from its neighbours by, a greatly thickened endomysium while each fasciculus was enveloped in a thickened perimysium. Despite the gross fibre atrophy and the connective tissue reaction there was no disorganization of the 
internal architecture of the muscle. The original fascicular pattern was preserved while there were no areas of replacement fibrosis to disturb the general fibre and fascicular pattern.

From these morphological findings we are not prepared to speculate on the outcome of events if the muscle is reinnervated after such long periods of denervation. What does occur under such circumstances can only be settled by experiment and not by inference based solely on morphological findings. Such an enquiry will form the subject of a separate communication.

The survival of muscle fibres under these experimental conditions should not be surprising in view of evidence that muscle may develop its characteristic features in the total absence of a nerve supply. Thus experimental embryology has provided numerous examples where grafted, or normal, limbs which have been deprived of a nerve supply during their development contain well-differentiated muscles and muscle fibres. Sherrington (1894-5) reporting on an amyelous fœtus wrote that "the striated muscles and their fibres revealed no obvious departure from the normal although the anterior cornual cells of the cord were non-existent", an arrangement which resembled that previously described by Leonowa (1893). Finally the presence of uninnervated muscle in teratomas possessing the characteristic morphological features of striated muscle is further evidence that a nerve supply is not essential for the development and preservation of those features upon which the recognition of striated muscle in histological preparations depends.

A study of the reported denervation changes in other mammals suggests, with the exception of Tower's account, that though there are minor differences from animal to animal and muscle to muscle, the overall picture is substantially the same. There appears to be general agreement between our findings in the opossum and those described by Bowden and Gutmann (1944) for human material with the following exceptions: a conspicuous increase in the connective tissue was apparent earlier in the opossum muscle while arterial thickening and obliteration were not observed in this mammal.

An investigation of our own denervation material from patients with peripheral nerve injuries, though they fail to provide the range and wealth of material which can be obtained experimentally, show a sequence of events which parallels that described in the opossum.

It is difficult to reconcile the findings reported in this paper with those described by Tower (1935) who followed the denervation changes in the fifth interosseous muscle of the cat for a year. She described more severe and destructive changes than any observed in our specimens. According to her a combination of acute degeneration occurring during the first six months with fibrotic dedifferentiation of the muscle fibres occurring thereafter deplete the muscle of its contractile elements and convert it into " a structure no longer muscle at all, but something between scar tissue and tendon".

We can only conclude that the profound changes which she reported are specific for the cat or for the muscle selected for study, namely the interosseous. It is to be remembered, however, that in her material the forelimb was totally denervated. Under such conditions it is reasonable to assume that vascular stasis and œdema would be a prominent feature of the dependent distal portion of the completely paralysed limb. Persistent disturbances of this nature could impair the nutrition of the limb and in this way modify the histological picture.

\section{Summary}

The response of mammalian striated muscle to denervation has been studied experimentally in the Australian opossum, Trichosurus vulpecula.

The duration of denervation in the shortest experiment was nine days and in the longest 485 days.

At no stage of denervation did the muscle give the appearance of becoming converted into an illdefined fibrous sheet. Even after 485 days of denervation the general form of each muscle was fully retained despite a reduction in size and weight, and each could be readily identified and easily removed. Fibrillation and shortening of the muscles on removal indicated that contractile tissue had survived the denervation.

Histological examination of the denervated material confirmed that the muscle fibres, though grossly atrophied, retained those histological features upon which the identification of striated muscle is based.

Following denervation there was a rapid initial loss of weight. The muscle sustained a $30 \%$ loss in 29 days which by 60 days had increased to 50 to $60 \%$. The process then slowed and a relatively stable state was reached somewhere about 120 days from which time onwards the weight loss varied between 60 and $80 \%$.

Individual muscle fibres atrophied rapidly in the initial stages so that at about 60 days the average fibre cross-sectional area was reduced by $70 \%$. The process then slowed appreciably so that approximately 60 days later (i.e. about 120 days after denervation) the atrophy had advanced only a further $10 \%$. From this time onwards the 
atrophy varied between 80 and $90 \%$. The reduction in the contractile component thus exceeded the weight loss of the entire muscle at all stages of denervation so that the fibres suffered more severely than the loss in weight of the muscle indicated. The latter therefore gives a false impression of the extent to which the contractile substance has reacted to the denervation.

The subsarcolemmal nuclei showed a preliminary enlargement but reverted to the original elongated form between 90 and 120 days when the fibre atrophy was well advanced. There were no signs of nuclear degeneration and counts failed to confirm any nuclear proliferation. No changes could be detected in the nucleoli. Though some nuclei adopted a central position the majority retained their original peripheral position. The gross atrophy of the fibre resulted in the nuclei occupying much more of the cross-sectional area of the fibres and this often created the appearance of a centrally placed nucleus.

Denervated fibres retained their characteristic striated appearance despite denervation for well over a year, though the striations were sometimes less prominent and intensely stained than normal.

Surviving fibres carried an end plate regardless of the period of denervation.

The degeneration of muscle fibres was rare even after periods of denervation of up to 485 days ; only two specimens showed degenerating fibres and signs of fibrous transformation.

Despite some atrophy of the intrafusal fibres the neuromuscular spindles retained their characteristic morphological appearance throughout the period of denervation.

A relative and absolute increase in the connective tissue content of the muscle in the form of a thickening of the perimysium and endomysium, particularly the former, was noted. A fibroblastic proliferation, which appeared between the sixteenth and twentyninth days and which reached a peak at 89 days, preceded the deposition of fibrillar material which involved the perimysium first and the endomysium later. From 56 days onwards the connective tissue fibres became coarser and more closely packed until a relatively stable state was reached at 89 days. At this time each atrophied fibre was enclosed in, and separated from its neighbours by, a greatly thickened endomysium while each fasciculus was enveloped in a thickened perimysium. Despite the gross fibre atrophy and the connective tissue reaction there was no disorganization of the internal architecture of the muscle. The original fascicular pattern was preserved while there were no areas of replacement fibrosis to disturb the general fibre and fascicular pattern.
With two exceptions the vascular picture in the denervated material was within the range of normal variation.

The endoneurial tubes atrophied progressively with increased periods of denervation, but tubes were still visible after 485 days though none exceeded $2 \mu$ in diameter; at this time the pathways of the denervated nerves were still well delineated.

\section{REFERENCES}

Altschul, R. (1942). Arch. Path., 34, 982. (1948). Anat. Rec., 100, 517.

Audova, A. (1923). Skand. Arch. Physiol., 44, 1.

Batten, F. E. (1897). Brain, 20, 138.

Bowden, R. E. M., and Gutmann, E. (194i). Ibid., 67, 273.

Chen, K. K., Meek, W., and Bradley, H. C. (1924). J. biol. Chem., 61, 807 .

Chor, H., Dolkart, R. E., and Davenport, H. A. (1937). Amer. J. Physiol., 118, 580.

Lenny-Brown, D., and Pennybacker, J. B. (1938). Brain, 61, 311.

Erb, W. (1868). Dtsch. Arch. klin. Med., 4, 535. Cited by Chen, Meek, and Bradley (1924).

(1869). Ibid., 5, 42. Cited by Chen, Meek, and Bradley (1924).

Fischer, E. (1940). Amer. J. Physiol., 131, 156.

Grund, G. (1912). Arch. exp. Path. Pharmak., 67, 393.

Gutmann, E. (1948). J. Neurophysiol., 11, 279.

- , and Young, J. Z. (1944). J. Anat., Lond., 78, 15.

Hines, H. M., and Knowlton, G. C. (1933). Amer. J Physiol., 104, 379.

Horsley, V. (1897). Brain, 20, 375.

Jamin, F. (1904). "Experimentelle Untersuchungen" zur Lehre von der Atrophie gelähmter Muskeln." Jena. Cited by Chen, Meek, and Bradley (1924).

Knowlton, G. C., and Hines, H. M. (1936). Proc. Soc. exp. Biol., N.Y., 35, 394.

Kopits, I. (1929). Arch. Orthop., 27, 277.

Krauss, E. (1888). Virchows Arch., 113, 315.

Langley, J. N. (1916). J. Physiol., 50, 335.

-(1917). Ibid., 51, 377.

__, and Hashimoto, M. (1918). Ibid., 52, 15.

__, and Kato, T. (1915). Ibid., 49, 432.

Leonowa, O. v. (1893). Neurol. Zbl., 12, 218, 263. Cited by Sherrington (1894), p. 249.

Lippmann, R. K., and Selig, S. (1928). Surg. Gynec. Obstet., 47, 512.

Lipschütz, A., and Audova, A. (1921). J. Physiol., 55, 300 .

Reid, G. (1941). Med. J. Aust., 2, 165.

Ricker, G. (1901). Virchows Arch., 165, 263.

__, and Ellenbeck, J. (1899). Ibid., 158, 199.

Roberts, F. (1916). Brain, 39, 297.

Schiff, M. (1851). Arch. physiol. Heilkunde, 10, 579, 665. Cited by Tower (1939). Physiol. Rev., 19, 1.

Schmidtmann, M. (1916). Zbl. allg. Path. path. Anat., 27, 337.

Sherrington, C. S. (1894). J. Physiol., 17, 211. 
Solandt, D. Y. (1942). J. Amer. med. Ass., 120, 511. DeLury, D. B., and Hunter, J. (1943). Amer. J. Physiol., 140, 247.

and Magladery, J. W. (1940). Brain, 63, 255.

Stier, S. (1896). Arch. Psychiat. Nervenkr., 29, 249.

Strümpell, A. (1894). "Lehrbuch der speciellen Pathologie und Therapie der inneren Krankheiten ", 8 th ed. Leipzig. Cited by Chen, Meek, and Bradley (1924).
Thompson, T. C. (1934). J. Bone Jt Surg., 16, 564.

Tower, S. S. (1932). Brain, 55, 77.

(1935). Amer. J. Anat., 56, 1.

(1939a). Physiol. Rev., 19, 1.

(1939b). Arch. Neurol. Psychiat., 42, 219.

Weiss, P., and Edds, M. V. (1946). Amer. J. Physiol., 145, 587.

Willard, W. A., and Grau, E. C. (1924). Anat. Rec., 27, 192.

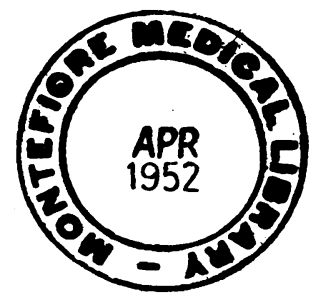

